\title{
Reasons: Practical and Adaptive ${ }^{1}$
}

\section{Joseph Raz}

I will consider some of the differences between epistemic reasons and reasons for action, and use these differences to illuminate a major division between types of normative reasons ${ }^{2}$, which I will call 'adaptive' and 'practical' reasons. A few clarifications of some aspects of the concept of epistemic reasons will lead to a distinction between standard and non-standard reasons (section I). Some differences between epistemic and practical reasons will be described and explained in section 2, paving the way to generalising the contrast and explaining the difference between adaptive and practical reasons (section 3). Sections $4 \& 5$ further explain and defend the views of the preceding sections. My ultimate goal is an explanation of normativity. But the present paper does more to explain a difficulty such an explanation faces than to resolve it.

\section{Standard and Non-Standard Reasons}

Reasons for action, I will assume, are facts which constitute a case for (or against) the performance of an action. Epistemic reasons are reasons for believing in a proposition through being facts which are part of a case for (belief in) its truth (call such considerations 'truth-related'). These maxims (as I shall call them) have proved controversial. Confining myself to the epistemic maxim two clarifications and one argument may help.

The first clarification concerns the question what determines whether available epistemic reasons are sufficient to warrant belief. It is not my view that only truth-

I The first draft was presented at a conference on practical reason at Bowling Green April 7-9, 2006. Parts of it were presented on various subsequent occasions. I am grateful for comments given me at the conference, and by others, including Stephen Everson, Ulrike Heuer, Mark Kalderon, David Owens, Anthony Price, Peter Railton and Kieran Setiya.

$2 \quad$ On the difference between, and the relations of normative and explanatory reasons see my 'Reasons: Normative and Explanatory'. I will generally use 'reasons' to refer to normative reasons, adding the adjective only occasionally to underline the point. Reasons are inherently relational. ' $\mathrm{P}$ is a reason' means that there is someone and some action or belief so that $\mathrm{P}$ is a reason for that person to have that belief or to perform that action. The same is true of evidence: ' $E$ is evidence for $P$ ' means that there is someone such that at a particular time $E$ is for that person a reason to believe that $P$. 
related considerations figure among those determining the sufficiency of the case. However, the factors or principles which determine whether the case for the truth of a proposition is adequate to warrant belief are not themselves reasons for belief. Therefore, the maxim is not affected by this point. ${ }^{3}$

The second clarification concerns arguments that simplicity, elegance, explanatory power, or other such considerations govern rational belief or theory acceptance. The maxim is consistent with such views, so long as theory acceptance is understood for what it is: acceptance of theories, not belief in them. The maxim is about reasons for belief only. It denies that the simplicity of a proposition or a theory is always a reason to believe it. But such considerations may be relevant to acceptance of propositions. As Ulrike Heuer suggested to me, accepting a proposition is conducting oneself in accord with the belief that there is sufficient reason to act on the assumption that the proposition is true: acceptance of the proposition that $\mathrm{P}$ entails belief, but not belief that $P$. Rather it entails belief that it is justified to act as if $P$. Thus acceptance combines epistemic and practical reasons, though its target is action rather than belief. Acceptance dominates many areas of practical thought. The whole system of law enforcement via courts and tribunals is based on acceptance of presumptions, like the presumption of innocence, and on accepting verdicts based on evidence presented in court, while ignoring all other evidence. Juries and judges are not required to believe that the accused is guilty or innocent. They are only required to accept and pronounce verdicts which are correct according to the evidence before them. Often other people who do not believe that the verdict is correct have compelling reasons to conduct themselves as if it were correct, that is to accept its content.

My one argument in support of the maxim is directed against the suggestion that since believing something can have benefits or disadvantages independently of the truth of what is believed there can be epistemic reasons which are not part of the case for its truth. For example, should an evil demon credibly threaten to punish me unless I believe something, would that not be a reason to believe that something? Perhaps it is. I will

3 See for example S. Stroud in 'Epistemic Partiality in Friendship' Ethics (2006) 498, in support of the relevance of non-truth-related considerations. 
return to that question in section 3.4. For the moment let us accept a terminological convention and continue to call the truth-related reasons for belief epistemic reasons. The others are practical reasons, perhaps they are practical reasons for belief. There are fundamental differences between truth-related and non-truth-related reasons for belief which show that the latter are practical.

Among others, truth-related considerations differ from other alleged reasons for belief in two important respects. First, one who believes that there is a conclusive case for the truth of a proposition cannot but believe that proposition (pathological cases ${ }^{4}$ apart). There is no gap, no extra step in reasoning, between believing that the case for the truth of the proposition is conclusive and believing the proposition. Similarly, there is no gap between believing that the case for the truth of a proposition is inadequate and withholding belief in it. ${ }^{5}$ More directly and more generally (and again excepting pathologies), reasoning from (what we treat as) reasons for belief to a conclusion (from: 'the door is open' to 'therefore anyone could have walked in') we acquire the belief as we arrive at the conclusion. As we conclude that therefore anyone could have walked in, we come to believe that anyone could have walked in. By way of contrast, one cannot similarly reason from a non-truth-related reason for having a belief to having that belief. I cannot believe that Bush is a good president because I believe that I would get a plum job offer if I did so believe. All that is conceptually possible for us to conclude is that we should believe that Bush is a good president. But that is a different conclusion. It too is a belief, but a different one. Of course if we should believe that Bush is a good president then we have reason to bring it about that we so believe.

$4 \quad$ Pathological cases are ones where some of the conditions which constitute belief are met while others are not. There are many possible pathologies. One simple one is when one manifests all the criteria for such a belief, except in a particular context, say when thinking about one's relations with one's parents, when the belief sort of disappears.

These claims require a more elaborate, qualified and subtle formulation than I can give them. For an argument for a position a good deal stronger than the two claims I make here see J. Adler

Beliefs Own Ethics (MIT Press 2002). For various discussions of non-truth-related reasons see Gilbert Harman, 'Rationality', repr. In G. Harman, Reasoning, Meaning and Mind (Oxford: OUP 1999); Derek Parfit, "Rationality and Reasons," in Exploring Practical Philosophy, ed. Dan Egonsson, et al. (Burlington, VT: Ashgate Press, 200I); Jonas Olson, "Buck-Passing and the Wrong Kind of Reasons," The Philosophical Quarterly 54 (2004); Justin D'Arms and Daniel Jacobson, "Sentiment and Value," Ethics I 10 (2000); Wlodek Rabinowitz and Toni RønnowRasmussen, "The Strike of the Demon: On Fitting Pro-Attitudes and Value," Ethics I I4 (2004), Pamela Hieronymi, "The Wrong Kind of Reason," Journal of Philosophy 102 (2005) 437. 
Needless to say belief in the advantages I will enjoy if I believe that Bush is a good president can cause me to deceive myself into believing that there are adequate truth-related reasons to believe that Bush is a good president. But that does not undermine the contrast between truth-related and other considerations to which I pointed. ${ }^{6}$

Second, think of the distinction, familiar from practical reasons, between conforming with reasons and following them. A reason to $\Phi$ is conformed with when one $\Phi s$, and is followed when one $\Phi$ s for that reason. In some cases conforming requires following: Some reasons are reasons not merely to perform an action, but to perform it for a reason (this is normally the case when the reason is to perform the action intentionally), and some reasons require performing it for that very same reason (one's love may be a reason to perform actions out of love). Often, however, reasons are reasons to perform the action, regardless of the reason why. I sometimes find myself in my office at a time I promised to be there, even though I forgot about the promise. Still, I did all I promised to do. I conformed to the reason my promise is. Applying an intuitively analogous distinction to theoretical reasons, we see that in coming to believe what one has non-truth-related reasons to believe one conforms to those reasons, but one cannot come to that belief by following them. One cannot come to believe a proposition for the reason that there are non-truth-related normative reasons for having that belief. That cannot be one's reason for holding that belief. By way of contrast one can come to have a belief by following truth-related reasons for it. One can have the belief for which they are reasons, and one can have it for those reasons. $^{7}$

These considerations, especially the second one, suggest a distinction between standard and non-standard reasons for action, belief, intention, emotion or whatever. Standard reasons are those which we can follow directly, that is have the attitude, or

6 This failure of the simple route to a belief is (a generalised form of) Williams's condition that one reaches the belief 'because in some way he is considering the matter aright' (op.cit.). See also section 4 of my 'Reasons: normative and explanatory'.

The same points are at the core of N. Shah's 'A new argument for evidentialism' Philosophical Quarterly 56 (2006) 48I. 
perform the action, for that reason. Non-standard reasons for an action or an attitude are such that one can conform to, but not follow directly.

The importance of the distinction is shown by its relevance to many other issues. Not least that having a belief for adequate truth-related reasons is rational, and having it for non-truth-related reasons (i.e. when one's [belief in] non-truth-related reasons to believe is - part of - the explanation of why one believes), even if useful and desirable, is irrational. This vindicates a familiar thought: epistemic reasons can warrant belief. Nontruth-related reasons cannot. So while it may be best (because it is advantageous, or conducive to the common good, etc.) to believe that, e.g., one's loved ones are in perfect health, or that one will win a competition, the factors which make it so are not epistemic reasons for that belief. They are non-standard practical reasons for having the belief.

\section{Epistemic Reasons \& Reasons for Action - Some Differences}

It is time to turn to the difference between reasons for action and epistemic reasons. I will focus on evidence-based reasons. Here are some others: That today is Friday the 17th is reason to believe that Sunday will be the 19th. That the visitor I expect is a bachelor is reason to believe that he is male. That citizens have a right to vote in elections and that you are a citizen, is reason to believe that you have a right to vote. Logical, conceptual, norm-based, expert-based, testimonial and other epistemic reasons differ from evidence in important respects. The crucial differences, the first two below, apply to all of them, and that makes it unnecessary to discuss them separately.

\section{a) The first two: Pluralism and Value}

Two fundamental differences between epistemic and practical reasons ${ }^{8}$ follow from the maxims. Epistemic reasons are governed by one concern: determination whether the belief for which they are reasons is or is not true. Reasons for a single action may, and typically are, governed by many concerns. A single action can serve or

$8 \quad$ As indicated at the outset I will argue that reasons for action are but one kind of practical reasons. However, to expedite expression I will refer to them using the generic category, 'practical reasons' rather than the less flexible in use 'reasons for action'. What I say is meant to be true of all practical reasons. 
disserve a number of intrinsic values: It may be an act of friendship and of justice. Moreover, even when the reasons for an action derive from a single value the action may serve independent concerns: a single act can advance the welfare of several individuals, when the interest of each of them is a reason, an independent reason, to perform it. ${ }^{9}$ To the extent that reasons for action represent independent concerns, we have reason to satisfy all of them. When reasons deriving from independent concerns conflict it is impossible to do so. In that case whatever we do some of the concerns which generate reasons for us will remain unsatisfied (by our actions at the time).

Hence when (independent) reasons for action conflict, even when it is clear which action is supported by the better reason, there is some loss, consisting in the fact that even when we successfully do our best there are concerns that we have reason to meet or satisfy which were left unsatisfied. Typically, concerns which remain unsatisfied provide reason for some action in the future, to satisfy them, or if impossible (or unjustified because of further conflicts) to do the second best, to come as close to satisfying them as possible (which is what compensation often is). If I have reason to have a relaxed weekend by the seaside and a stronger conflicting reason to work in the office to meet an urgent deadline, then I should work in the office and find a way of taking half a day off on Monday to get at least some holiday.

There is no close analogue of the need to satisfy independent concerns and therefore no close analogue of reasons for compensatory actions in epistemic reasons. Epistemic reasons can conflict, but all of them are about the truth of the propositions for or against belief in which they are reasons. The weaker reasons are just less reliable guides to one and the same end. There is no loss in dismissing a less reliable clue. This is a fundamental difference between epistemic and practical reasons. Noting this difference Susan Hurley ${ }^{10}$ compared reasons for belief to rules of thumb, useful when useful, but

9 See my “Personal Practical Conflicts”, Practical Conflicts: New Philosophical Essays eds. P. Baumann \& M. Betzler (NY: CUP 2004) 172.

10 S. Hurley, Natural Reasons (Oxford: O.U.P. 1989) I30-135. The argument is not conclusive, but the case for epistemic akrasia is not the current subject. The disanalogy Hurley points to is real enough. 
happily replaced when better ones are available. She used this difference between practical and epistemic reasons to explain the absence of epistemic akrasia.

To put it in my own terms: because there is no possibility that the lesser reason for belief serves a concern which is not served better by the better reason there is no possibility of preferring to follow what one takes to be the lesser reason rather than the better one. The possibility of akrasia depends on the fact that belief that a practical reason is defeated by a better conflicting reason is consistent with belief that it serves a concern which the better reason does not, and which can motivate one to follow it.

So far I argued that practical reasons serve many concerns and epistemic ones can serve only one. It is tempting to explain this by saying that practical reasons derive from many values, whereas epistemic reasons derive from one value only, presumably the value of having true beliefs, or two, the values of having true beliefs and of not having false ones. I think that there is some, though only some, truth in the first half of that proposition: the value of actions constitutes reasons for them and as actions can have many distinct evaluative properties there are many concerns those reasons express. But reasons for belief are not similarly connected to values, not even to a single value.

First, the diversity of concerns manifested in practical reasons is not entirely due to the diversity of values. Diverse values do generate diverse concerns, but so do other factors: For example, being a medically qualified caretaker of sheltered accommodation for disabled people I have a reason to help anyone there who needs insulin injections. There are several such people. So I have a reason to help each of them. Each of these reasons represents an independent concern, and they can conflict with each other, even though they all derive from the same value.

Second, epistemic reasons do not derive from the value of having that belief in the way that reasons for an action derive from the value of that action. It is not the case that there is always value in having a true belief, whatever it is. Nor is it the case that it is always a disvalue to have a false belief. If that is so, and since there can always be reasons for believing at least any true proposition, it follows that reasons for belief are not provided by values in the way that reasons for action are. 
To maintain that reasons for belief do not derive from the value of having true beliefs one need not deny that often having true beliefs is instrumentally valuable, nor that there are some types of beliefs such that having true, or warranted true beliefs of those kinds is intrinsically valuable. The point is about epistemic reasons. Whether or not there are adequate reasons to believe in a proposition is a question unrelated to the value of having that belief. It is not the case that there are reasons for belief only when there is value in the belief. That is all that is required to show that reasons for a belief do not derive from the value of the belief in the way that reasons for an action derive from the value of the action. ${ }^{\prime \prime}$

To argue to the contrary one needs to establish that if we have a belief it is better that it be true than false, or that it be warranted than unwarranted, or some variants of these. In considering such claims we have to dismiss as irrelevant two slightly different views. First, that on balance given that true beliefs are less likely to mislead than false ones, it is (instrumentally) better that one's beliefs be true. Whatever the truth of the generalisation it does not warrant the conclusion that regarding any one of one's beliefs it is better that it be true than false. Second, while the fact that one's beliefs are warranted is evidence that one is functioning rationally, it does not follow, even assuming that it is good to function rationally, that it is better to have warranted than unwarranted beliefs (only that it is a by product of something good). Given these points it is hard to see what is meant by affirming the value of having true beliefs other than that true beliefs are correct, that is true.

Imagine the contrary, that is imagine that in all cases, if we have a belief about a certain matter then it is better to have a true rather than a false belief, just because it is true. Consider an example: A month ahead of time I believe that Red Rod will win the Derby or that the Social-Democrats will win the elections in Denmark. There may be ways to increase the likelihood that my belief is true. Perhaps I could give valuable advice to Red Rod's jockey, or lend my expertise to the Social-Democrats. Is the fact

11 The same goes for knowledge. There is no value in having knowledge as such, and reasons which underwrite knowledge do not depend on the value of having that knowledge. For a survey of recent writings on the value of knowledge see D. Prichard, 'Recent Work on Epistemic Value' American Phil. Quar. 44 (2007) 85. 
that that will make it more likely that my beliefs are true a reason to do so? If there is value in one's beliefs being true as such then there should be no difference between making reality conform to the belief and making the belief conform to how things are.

\section{b) Third Difference: Presumptive Sufficiency}

The value-independent character of epistemic reasons has important implications which will occupy much of the rest of this article. Here I will argue that it is responsible for another difference between epistemic and practical reasons. Practical reasons are presumptively sufficient. Epistemic reasons are not necessarily so. To see this we need to recall that often what appear to be references to several reasons may be references to one and the same reason. That my mother is in hospital, that there is a rail strike today, that she forgot her slippers at home may all be cited by me as my reason for heading towards the bus stop. But clearly they all refer to one reason. Facts which are part of a reason are commonly stated as a way of referring to the (complete) reason of which they are a part.

A (complete) reason to $\Phi$ at a particular time is presumptively sufficient because if there is no other reason either for or against so acting then (a) $\Phi$-ing at that time is justified, and (b) if the agent rationally believes that the reason applies, and that there is no other, then his failing to try to $\Phi$ is akratic. ${ }^{12}$

Things are different with epistemic reasons. ${ }^{13}$ Even if at a particular time there is only one reason for the agent to believe that a particular proposition is true, and no reason against that belief, coming to have that belief on the strength of that reason may be unjustified and irrational, and failing to do so may be justified and rational. Even a

12 Michael Stocker and Jonathan Dancy are among writers who reject the second feature. I find their views difficult to sustain, but we need not consider them here. The first feature is sufficient to establish the difference between practical and epistemic reasons. See, e.g., Stocker, 'Raz on the Intelligibility of Bad Acts' and Dancy, 'Enticing Reasons' in R.J. Wallace, P. Pettit, S. Scheffler \& M. Smith (eds.), Reason And Value, Oxford UP 2004.

13 See Engaging Reason (Oxford: OUP 2000) ; and David Owens, 'Epistemic Akrasia' The Monist 85 (2002) 381, 382-3 
good and undefeated epistemic reason may be insufficient to warrant belief. It may support it, but not be sufficient to warrant it. ${ }^{14}$

One may object that it is possible to define epistemic reasons as reasons which warrant belief, thus eliminating the difference between the two kinds of reason. Such a move is, however, too artificial to make any difference. We can identify practical reasons independently of whether they are presumptively sufficient, simply by identifying their normative force. We then show by example or argument that they are presumptively sufficient. If one insists on defining complete epistemic reasons as those which are presumptively sufficient to warrant belief it would follow that there are good, independent epistemic reasons, which are not complete reasons. They nevertheless have normative force and that would be enough to establish the difference between practical and epistemic reasons, as there are no practical reasons with normative force which are not sufficient to warrant action.

This contrast between epistemic and practical reasons is made possible by an important difference between belief and action. We can suspend belief, but not suspend action. Suspending belief means believing neither the proposition nor its contradictory. But there is no third option between doing an action and not doing it. If not performing an action is the contradictory of performing it then suspension of action, that is neither performing it nor not performing it, is not possible. But while this difference between action and belief makes room for the possibility of undefeated epistemic reasons which do not warrant beliefs, it does not in itself explain the difference. The explanation for this lies in the first two differences. Given that epistemic reasons are governed by a single concern they have, as we saw, the character of clues, and like clues they may be both good clues and insufficient to enable one to rationally form a view about the solution. Analogously, evidence may be good evidence but insufficient to warrant belief. On the other hand, a practical reason exists only if there is some good or some point in performing the action for which it is a reason. This is what it is to be a reason, to be a

14 For a contrary view see D. Davidson, 'How is Weakness of the Will Possible?' J. Feinberg (ed.) Moral Concepts (Oxford: OUP 1970), repr. Davidson, Actions \& Events (Oxford: OUP 1980) 21 . 
fact which confers value or point on the action. Hence, a single reason is sufficient to give point or value to the action, and absent any other reason it is sufficient to justify it.

\section{Generalizing the Contrast: Practical \& Adaptive Reasons}

Reasons (taken together) determine the ways people should relate to the world, in their beliefs, emotions, actions, and the like. But epistemic and practical reasons do so in fundamentally different ways. Briefly stated the basic difference between practical and epistemic reasons is that practical reasons, taken together, determine what and how, in light of the value of things, we should change or preserve in ourselves or the world. Epistemic reasons do not. They determine the way our beliefs should adjust to track how things are.

There are other normative reasons. Do they divide into two classes of which reasons for action and epistemic reasons are examples? For lack of appropriate terminology I will use 'practical reasons' to designate the class of which reasons for action are an instance, and 'adaptive reasons' to designate the class to which epistemic reasons belong. Reasons which are value-related are practical reasons, even if they are reasons for having a belief, or an emotion. Reasons are adaptive if they mark the appropriateness of an attitude in the agent independently of the value of having that attitude, its appropriateness to the way things are. Are there other instances of these types?

\section{a) The Case of Emotions}

Standard reasons for belief are adaptive, while non-standard reasons for belief are practical. How about reasons for or against having an emotion? I will just introduce the topic which is too large to deal with here. The role of reasons in our emotional life is very different from their role in our beliefs. I will mention only two differences. First, reasons allow much greater latitude regarding whether an emotion is required. For the most part even when appropriate there is nothing amiss in not having it. Fear is appropriate when facing great danger, but only exceptionally would its absence when in danger be against reason. Nor is its appropriate degree strictly regulated by reason. Second, emotions do not necessarily respond to reasons with the immediacy which characterises belief's relationship to reasons. When convinced that a belief is not 
supported by reasons we lose the belief, but typically realising that we were mistaken to think that there were reasons for an emotion does not instantly kill off the emotion. A period of adjustment is usually needed. These and other differences notwithstanding, emotions, like beliefs, are subject to at least two kinds of reasons. For we can usefully distinguish between affect-justifying reasons for emotions and practical reasons for having an emotions, which are not affect-justifying reasons.

Affect-justifying reasons are part of a case for the emotion being an appropriate response to how things are. Affect-justifying reasons are reasons awareness of which could rationally induce, as well as (other things being equal) establish the rationality of, having an emotion. Having been insulted is an affect-justifying reason for resentment. The fact that anger with one's competitor may, in the circumstances, improve one's chances of winning the competition is not an affect-justifying reason. Absent any other reason for anger, it will be irrational to be angry for that reason. ${ }^{15}$ But that anger will help one win the competition is a practical reason (not necessarily a sufficient one) for experiencing that emotion.

Affect-justifying reasons are adaptive. We can test their independence of value as before: Given that I am afraid of the journey (for no reason) do I have any reason at all to make my journey dangerous and make my fear appropriate? Given that I am jealous of Abe, do I have any reason to induce Abe to do something which will give me reason to be jealous of him? Only in jokes. The same applies to other emotions: we have adaptive reasons that they be appropriate given how things stand. But it is not the case that when we have an emotion there is always value in it being appropriate. Sometimes this is so, but sometimes the reverse is the case.

To be sure, the very meaning of 'appropriate to the way things are' when applied to emotions, is problematic in ways in which the appropriateness to the way things are

15 Judgements of irrationality are notoriously tricky to analyse. One complication regarding the rationality of the emotions results from the fact that we may have (sometimes conflicting) affectjustifying and practical reasons for them. Anger with my competitor, deliberately induced to help me win the competition, may, in so far as it was so induced, not be irrational, while being irrational in so far as my competitor did nothing to merit that anger. Perhaps the best way to sort out this apparent conflict is to say that my inducing the anger was not irrational, even though being angry is irrational. 
of true beliefs is not. Possibly the concept is incoherent. Possibly emotions are appropriate just in case that beliefs, which are part of what makes them the kind of emotions they are, are true. This may be related to the fact that some emotions appear not to have appropriate reasons. A murderous rage, for example, appears never to be appropriate, perhaps because there is no belief which one must have to have the emotion. This would explain why it is not irrational to feel murderous rage. It is just immoral. Generally speaking, an emotion is irrational if one experiences it without there being an adaptive reason for having it. But this is so only if there can be adaptive reasons for it. Where none can exist neither experiencing nor not experiencing the emotion can be rational or irrational, though there can be practical reasons for or against having it. This is not the place to consider these vexed matters. For our purposes suffice it to establish that affect-justifying reasons are not value-related.

This would explain why there can be adaptive reasons for having emotions which it is always wrong to have. For example, some people believe that there is never a good reason to be envious. They must refer to practical reasons, for surely there are adaptive reasons for envy. If you envy someone his victory then you have no reason to envy him if he did not in fact win, if you are mistaken about his victory. If you continue to envy him after your mistake has been corrected, you are irrational. If he was victorious then you may have an emotion which it is bad or wrong to have, but you are not irrational.

So far so similar to beliefs - affect-justifying reasons are the standard reasons for emotions, and they are adaptive. There are, however, also non-standard reasons for emotions, which are practical reasons. Arguably, however, matters are much more complex. As I have already mentioned, given the circumstances reasons for emotions may require an emotion. Not having the emotion in such circumstances may show a deficiency in the people concerned. But we are unlikely to take them to be factors which contribute to a judgement that the person lacking the emotion is irrational. Furthermore, at least sometimes the deficiency may be a moral deficiency. Think, e.g., of people who do not feel compassion when it is appropriate, and 'required', as it were, to feel compassion. We are likely to think of this as a moral blemish, but not as a case of irrationality, not even if the person believes that compassion is required. Why not? Does it mean that the reason for the emotion is a moral, therefore a practical reason? 
That would show that there are standard practical reasons for emotions. But it would not explain why flouting them is not irrational, even if one is aware that one is flouting them.

But perhaps even though the emotion is a moral emotion, and its inappropriate absence or presence is a moral defect, the reason for the emotion is an adaptive reason. We can compare these cases to the moral deficiency betrayed by one's beliefs, which does not show that the reasons for the beliefs are themselves practical reasons. That would explain why the deficiency does not affect judgement of rationality (the reasons are adaptive, and we assume permissive in the cases under consideration) while also explaining how emotions can contribute to the evaluation of the morality of one's life or character.

\section{b) Actions}

There seem to be no adaptive reasons for actions, no sense of a reason for action which is unrelated to its value. Does the fact that all reasons for action are practical reasons mean that there are no non-standard reasons for action? Or does it mean that they require some alternative explanation? I think that the latter is the case.

The case for there being non-standard reasons for action arises out of the familiar case of actions which have a certain value only if they are not performed in order to realise that value. Some may say that where the value of an action cannot be realised if it is done in order to realise it then that value does not provide a reason for the action which would have it. The alternative is to take it as providing a reason to perform the action but not for that reason. In other words, the value of the action is a reason which is conformed with only if it is not followed. Performance of the act which manifests the value need not be coincidental. We may create some other reasons (e.g. by an appropriate bet, or by habituation to follow an appropriate rule) for performing the action. ${ }^{16}$ (Such manipulation is not always possible, but then not always can we

16 We may want to distinguish two senses of following a reason: ( 1 ) one follows a reason to $\Phi$ which applies to one if, for that reason, one does something to facilitate one's $\Phi$-ing, and (2) one follows a reason to $\Phi$ if one $\Phi$ s for that reason. Where an action has value only if performed not in order to realise that value it can be followed in sense (I), but not in sense (2) which is the standard sense of the expression (and to which I referred earlier as 'directly following'). 
conform to reasons which apply to us). This suggests that even such values provide reasons for the actions which have them.

These will be, though, non-standard reasons for action. The value of the action cannot be the reason for which the action is done: We cannot successfully perform the action we have reason to perform for that reason (because the action we have reason to perform is 'to perform a specific act but not for that reason'). But the reason is a reason to get ourselves to perform the action. So it seems that there are both standard and non-standard reasons for action, both kinds being practical reasons.

\section{c) Intentions}

Intentions present complications of their own. Reasons for action are either reasons for intentional actions, or for actions which need not be intentional. Put another way, practical reasons may be conformed to either only by an intentional action, or by actions which need not be intentional. Either way they are also reasons for intending the action, because performing it intentionally is a way of performing it. ${ }^{17}$ If the reason is to perform an intentional action then having the intention is necessary for conforming with the reason. But even if the action need not be intentional intending it is the normal way to secure its performance, and therefore an undefeated reason for the action is also a reason for intending it.

Reasons to $\Phi$ are standard reasons for intending to $\Phi$. But there can be others. There can be reasons to intend an action which are independent of whether there is reason for the action. I will call them independent reasons (for intentions). For example, it may be a good thing to reassure some people that I will perform an action, say in a year's time. This may be so even though there is no reason to perform the action. ${ }^{18}$ If I now intend to perform the action they will be reassured. So I have a reason to intend to perform an action which I do not have, and I know that I do not have, adequate reason to perform. A few months down the line that reason may disappear (e.g. it may become

17 Reasons to perform an action unintentionally are the sole exception to the above.

18 The Toxin Puzzle (Gregory Kavka, 'The Toxin Puzzle', Analysis 43 (1983) 33) raises the question whether when we believe that there is reason against an act we can still respond to a reason for having the intention. The phenomenon here discussed is wider, in not relying on a belief that there are reasons against the act. 
clear that the action will be performed anyway, if not by this agent then by another). In fact the agent never performs the action. Nevertheless he had a reason to intend it at the time. ${ }^{19}$

Just as a reason to perform an action is also a reason to intend the action so, at least in many cases, an independent reason to intend an action is, ipso facto, a reason to perform the action so intended. Sometimes this will be so because it is impossible to intend to $\Phi$ without $\Phi$-ing, as is the case when the intention is the one embedded in the action (the intention with which we perform an intentional action), or more generally, when performing the action will make it easier to have the intention to perform it we may have a reason to perform the action to facilitate having the intention.

The question is: is it possible to intend to perform an action, which we do not believe that we have any (other) reason to perform, for an independent reason for that intention? We can manipulate ourselves to have such an intention, for example by inducing in ourselves false beliefs about the case for the action, and we can come to have such beliefs through self-deception. We may even be able to create reasons to perform the action (e.g. promise to do so) thus making it possible to intend to perform it. Such cases do not show that it is possible to intend to perform an action for an independent reason. If they are the only ways in which we can follow independent reasons for having an intention then such reasons are non-standard. Like other nonstandard reasons they are practical reasons. If so then as with reasons for action, both standard and non-standard reasons for having intentions are practical reasons.

To examine the matter suppose that one has an intention which one has only independent reasons to have. Regarding beliefs, emotions and actions, if they need to be supported by what the agents take to be adequate reasons to be rational then they are irrational if agents believe that they are supported only by non-standard reasons. Emotions and beliefs are irrational in these circumstances because the reasons needed to make them rational are adaptive reasons, and the agents believe that they are supported only by practical reasons. Actions are irrational in these circumstances action. I will disregard such cases. 
because while they are supported, as they should be, by practical reasons, these reasons are followed in a self-defeating way. Non- standard reasons for intentions are practical. So the question turns on whether directly following them is impossible or self-defeating.

Here is an example: suppose that you offer me something worth having (which there is no reason why I should not wish to receive from you) if I intend to move my hand, resting on the sofa, 5 inches to the left. You do not care whether or not I actually move my hand, and there are no other reasons I am or can become aware of which bear on either action or intention. I ask myself: should I form that intention, and of course that immediately raises in my mind the question about the action: should I move my hand? Yes I say, for if I do, I will be doing so intentionally, thus earning the offer. My deliberation relies on the fact that in the circumstances acting is a way of having the intention, hence the reason for the intention becomes a reason for the action. This kind of independent reason for an intention is therefore a standard reason for it.

Now suppose that your offer is on condition that I intend now to move my hand tomorrow (and that we know that there will be no other reason regarding the intention or the action tomorrow). You care neither whether I move my hand tomorrow nor whether I maintain my intention to move it for more than a few minutes. The difference being that in this case once I now intend to move my hand tomorrow I no longer have reason either to maintain the intention or to perform the action. I have already met the condition of the offer. The question is: can I form an intention now when I now believe that I will not have reason to maintain it or to act on it? If an intention presupposes belief that there is reason to perform the action one intends then I cannot form such an intention for the independent reason, for I do not now believe that there will be a reason to perform the action tomorrow. ${ }^{20}$ In conclusion independent reasons to form future directed intentions can be followed only indirectly, by making ourselves form them, but we cannot form future directed intentions for independent reasons.

Therefore independent reasons for future directed intentions are non-standard reasons.

A similar conclusion is arrived at by $\mathrm{N}$. Shah in 'How action governs intention', who writes: 'The constitutive norm for intention is this: intending to $A$ is correct only if $A$-ing is the thing to do.' However, he disregards the possibility that independent reasons to intend to $A$ provide reasons to $A$. 
But, both reasons for the (to be intended) action, and independent reasons for having the intention embedded in an intentional action are standard reasons for intentions.

\section{Standard and Non-standard Reasons - again}

The distinction between practical and adaptive reasons, as drawn here, depends on the prior distinction between standard and non-standard reasons. I identify nonstandard reasons as reasons for some action or attitude which cannot be (directly) followed (call this 'The Condition'). In discussion Kieran Setyah raised an objection, whose exploration will help clarify the nature of the distinction.

Can the standard/non-standard distinction rest on The can-be-directly-followed Condition? Is it not the case that anything which anyone takes to be a reason can be followed by that person? Is that not what we mean when saying that it is taken to be a reason? How can one take something to be a reason without following it as a reason?

Suppose that one replies that The Condition applies only to ("real") reasons. It is not a test by which to determine what is taken to be a reason and is not. There are independent ways of establishing whether a fact is a reason for someone to do something or to have some attitude. Allowing this point does not altogether resolve the difficulty. Suppose that a certain fact is a reason. For example, imagine that someone promises Jake a large sum of money if he believes that $\mathrm{P}$. By all accounts this is a reason to have that belief. I claim that it is a non-standard reason for it cannot be followed. But suppose that Jake does not think that. Suppose that he is philosophically minded (it is possible to develop the example so as to get rid of this assumption) and believes that the promise is an ordinary, standard, reason for believing that $\mathrm{P}$, and that as a result he comes to believe that P. Of course, I will say that he has not followed the reason that the promise gave him, that he deceives himself into believing that he followed the reason and that it is a standard reason for belief. Perhaps. But that cannot be established by The Condition. I am presupposing that he did not follow the reason because I take it not to be standard. But I have to establish that he did not follow the reason first. I have to establish this independently of assuming that the reason is not standard, for only this way would The following-a-reason Condition establish which reasons are standard. 
Could one reply that The Condition is about following-reasons-without-beingguilty-of-conceptual-confusions, whereas Jake is conceptually confused and only because of that can he follow the reason directly? But that reply concedes too much. It seems to me that the more accurate reply is that, just as in the case of "folllowing" something which is no reason at all, Jake merely thinks that he is following the reason, whereas in fact he does not. He is self-decieved.

That establishes that the question of whether one follows a reason is not purely a matter of how the agent understands his situation. To follow a reason he must behave in a way which is possible given the nature of that reason. That I am thirsty is a reason for me to drink the water in front of me. But it is not a reason to call my mother. Suppose that I say (bizzarely, but bizarre things happen) that my reason for calling my mother was that I was thirsty. Barring some complicated story to make the claim true, I am (a) confused, either conceptually, or about the nature of telephone calls, or about thirst, and (b) I did not follow that reason, I merely thought that I did. That much follows from the kind of reason that thirst is.

Two questions loom: First, does the nature of a reason also determine what it is a standard reason for (as I shall argue later any non-standard reason for one thing is a standard reason for another)? Second, is the claim that the nature of a reason determines what it is a reason for consistent with taking the possibility of following a reason as a mark of being a standard reason? The doubt embodied in the first question is that the non-standard reasons for belief, emotions, intentions, actions etc. are reasons for belief, emotions, intentions, actions, etc. The distinction between standard and nonstandard reasons depends, if you like, on more subtle factors. But are they part of the nature of the reasons?

Both questions can be answered in one by examining the factors which make it impossible to follow reasons, thus rendering them indirect. I can make no claim that the analysis of this article is exhaustive, but let me briefly recap the factors here explained, starting from the case of non-standard reasons for action and intentions. Here two kinds of factor may make a reason non-standard. First, if following it is self-defeating. Second, in the case of intentions, if the formation of the intention is impossible, as it 
violates some necessary condition for having an intention. These conditions are met when the reason for the action is a reason for an action not performed for that reason, and when reason for the intention does not provide a reason for the action (not even as a way of having or of facilitating the having of the intention). The existence or absence of these conditions does not presuppose any claim about the impossibility of following reasons which meet them. They are part of, or derive from, the character of those reasons, and the claim that reasons which meet the conditions cannot be followed results directly from them, ${ }^{21}$

Turn now to adaptive reasons for belief and emotions. Here the case is different. The reasons which are in fact non-standard do not comply with the maxims governing such reasons: they are not part of a case for the beliefs or emotions being appropriate (not part of the case for the truth of the belief, and whatever substitutes for truth in the case of various emotions). ${ }^{22}$ That too is part of the nature of the reasons. The question is: why does that show that the reasons cannot be followed? Here we need to rely on the various points made in drawing the distinction in section one (the case of emotions is analoguous, but their discussion here is too sketchy to allow one to do more than to rely on the analogy based on their character as adaptive reasons). Perhaps most importantly the fact that non-epistemic reasons cannot serve to warrant belief shows that they cannot be followed. Ultimately, however, the explanation of the force of this point depends on understanding the normativity of reasons, their hold on us, a matter I deal with elsewhere.

Setiya offers the following example: 'If you offer me a lot of money to intend to buy an apple tomorrow, it seems that I can follow that reason, deciding to buy an apple and doing so (so long as I think it is sufficiently likely that I will buy the apple tomorrow).' That seems to me to be mistaken. Whatever happens today, come tomorrow I will not buy the apple. I would not be able to think of a single reason to do so. (There is no problem if I can now think of a reason, independently of the offer, to buy an apple tomorrow - but that is irrelevant to our case). So I will not buy the apple. If I know that now (as I can do) then I know that buying the apple will not help me in forming the intention now to buy it tomorrow. So I have no reason to buy the apple, and your offer does not constitute one. Hence the offer, though it is a reason for having the intention, is not one which can be followed. Of course, people form intentions when they should know that that is silly so often that we think that we could do so in this case as well. And indeed if we are confused or mistaken we will succeed. But, when we do so we merely think that we follow the reason (if we do). We do not in fact do so.

Non-standard reasons for actions and intentions do conform to the maxims governing actions and intentions in being part of the case for the value or point of the actions or intentions. 


\section{Special Practical Reasons for Beliefs and Emotions?}

There is one last question to consider: we saw that there are standard and nonstandard reasons for actions and standard and non-standard reasons for having intentions. The question is are the practical reasons for having beliefs or emotions distinct types of practical reasons, on a par with reasons for actions and for intentions, or are they simply reasons for actions (and for intentions)? Surface appearances suggest that practical reasons for having beliefs and emotions are just that. They suggest that it distorts things to regard them as reasons for action. Perhaps they yield instrumental reasons for action, as the way of bringing it about that we conform to the primary reasons to have those beliefs and emotions. But it would merely distort things to deny that there are practical reasons for beliefs and for emotions.

But this argument from surface appearances is suspect. Consider: we have reasons to have efficient transport systems, and good housing. Does it mean that there are distinct transport and housing types of practical reasons? In a way there are, but that is simply to classify practical reasons by the subject matter they relate to. That is not the sense in which epistemic reasons differ from reasons for emotions, or reasons for actions differ from reasons for intentions. These distinctions are based on the thought that reasons are normative and we respond to them through recognising them as such. Our beliefs respond to reasons: as we recognise epistemic reasons our beliefs change in line with them. With due modifications the same is true of emotions, and of intentions. The basic classification of reasons is a classification of standard reasons, because the fact that they can be followed is what makes reasons into reasons.

We also respond to non-standard reasons for beliefs and emotions, but we do so directly by performing actions and only indirectly by changing our beliefs and emotions. Non-standard reasons for belief are like reasons for having good houses, they are reasons for actions which will have those results. The result is that all non-standard reasons are practical reasons. All non-standard reasons for one thing are standard reasons for another: a non-standard reason to believe that $\mathrm{P}$ is a standard reason to 
bring it about that I believe that $P .{ }^{23}$ A non-standard reason to $\Phi$ is a standard reason to bring it about that I $\Phi$.

This conclusion helps with some of the points raised in the discussion of the emotions above. For example, if one has an emotion which is not supported by adaptive reasons (where adaptive reasons are possible) it is an irrational emotion to have in the circumstances. But if one has an emotion in defiance of decisive practical reasons against having it one is morally or otherwise deficient, but not irrational. Why not? Is not defiance of (what are taken to be) valid reasons irrational? It is, but since the reasons are not really reasons for the emotions, since they are reasons for action to bring it about that one has the emotions, the irrationality is in the failure to try to prevent or suppress the emotions. If one tries and fails one is not irrational at all, but one is still morally or otherwise deficient.

Does that argument prove too much? Does it not show that there are no reasons for actions. only reasons for intending, for we can only respond to reasons to act by intending to act, just as we can only respond to non-standard reasons for belief, or to reasons for having good housing by acting? We know, of course, that reasons for action are primary, for standard reasons for intentions are reasons for the intended actions. But does not that simply undermine the argument I used in the previous paragraph? To think so is to misconceive the relations of intention and action, imagining that when acting intentionally one acts by forming an intention which causes one to act. In fact the intention of an intentional action is not a mental event separate from the action but an aspect of the action, the way it is performed. One responds to a (perceived) adequate reason to act by acting (intentionally). Sometimes we respond now to (as we see it) an adequate reason to act in the future by forming now an intention to act in the future. Future-directed intentions are separate from the actions. The reasons for them, though normally deriving from the reasons for the actions, are a distinctive kind of reasons simply in virtue of the fact that we respond to them directly by forming a reason to bring about that I believe that $P$. 
the intentions. But reasons for action do not require future-directed intentions. We can respond to them by acting. ${ }^{24}$

\section{Conclusion}

The distinction between adaptive and practical reasons has important consequences. For example, we may well say that practical and adaptive reasons do not conflict. While we may have epistemic reasons for a particular belief and a practical reason not to have it the two conflict neither in the way that two epistemic nor in the way that two practical reasons conflict. The outcome of "conflict" between adaptive and practical reasons is not, as in genuine conflict between practical reasons or between epistemic ones, that the better reason prevails. They are not in competition, and reasons of neither kind can be better than reasons of the other. Rather, adaptive reasons, being the standard reasons for belief or for having emotions, prevail. Practical reasons, being non-standard, can 'win' only by stealth. ${ }^{25}$ There is much here which remains to be explored, not least being the question: in what sense are reasons of the two types reasons in the same sense? This is due to their being normative in the same sense. These are mattes for another occasion. ${ }^{26}$ In this article I merely tried to help to sort out the terrain, to show that normativity is not to be explained by value, and to endorse one implication of Bernard Williams's work, namely that the key to normativity is in the concept of following a reason.

Scanlon's discussion of the same issue is similar in some respects, but he mistakenly concludes that 'judgement-sensitive attitudes constitute the class of things for which reasons in the standard normative sense can sensibly be asked for or offered' (What We Owe to Each Other, Harvard U.P. 1998, 21). The mistake leading to this conclusion is his view that 'actions are the kind of things for which normative reasons can be given only insofar as they are intentional, that is are the expression of judgement-sensitive attitudes'. That is at best ambiguous. Of course we respond to reasons intentionally. But it does not follow that reasons are always for intentional actions, that they can be conformed with only by intentional actions. There are plenty of reasons which are conformed with by actions, intentional or otherwise. Note though that standard and non-standard reasons for action, both being practical, do conflict in a straightforward way. And the same is true of reasons for intentions. 